\title{
Correction: Epidemiology of bloodstream infections in patients with chronic lymphocytic leukemia: a longitudinal nation-wide cohort study
}

\author{
Michael Asger Andersen · Claus Ernst Moser · Jens Lundgren · Carsten Utoft Niemann
}

Published online: 27 July 2020

(c) Springer Nature Limited 2020

Correction to: Leukemia

https://doi.org/10.1038/s41375-018-0316-5

Since the publication of the article, it has come to the authors' attention that the numbers used in in Table 2, Table 3, and Fig. 3 represents hospital-acquired bacteremias for the background population. This means that the background population did have Streptococcus Pneumonia in the top 10 most common pathogens, whereas they stated

otherwise in the paper. Therefore, the authors have provided updates to reflect this data more accurately. Reference 17 has been updated, and Fig. 3 and Table 3 and their legends have been updated. Table 2's legend now clarifies the original lack of data. The correct Reference 17, Fig. 3, and Tables 2 and 3 are produced below, and these have been updated in both the PDF and HTML versions of this paper.

Table 2 Standardized incidence ratios (SIRs) of bloodstream infections in patients with chronic lymphocytic leukemia (CLL) stratified according to age and treatment status, with treatment-naive (TN) and treated patients separately.

\begin{tabular}{|c|c|c|c|c|c|c|}
\hline Age group & Status & $\begin{array}{l}\text { Person } \\
\text { years }\end{array}$ & $\begin{array}{l}\text { Number of } \\
\text { bloodstream } \\
\text { infections }\end{array}$ & Incidence rate & $\begin{array}{l}\text { Expected } \\
\text { number of } \\
\text { bloodstream } \\
\text { infections }\end{array}$ & SIR $(95 \%$ CI) \\
\hline$<41$ & $\mathrm{TN}$ & 32.4 & 0 & 0 & 0 & $0(0-1301.7)$ \\
\hline $41-60$ & $\mathrm{TN}$ & 1681.9 & 13 & 7.7 & 0.6 & $21.8(11.6-37.3)$ \\
\hline $61-80$ & $\mathrm{TN}$ & 6153.1 & 100 & 16.3 & 8.2 & $12.3(10.0-14.9)$ \\
\hline$>80$ & $\mathrm{TN}$ & 1608.5 & 34 & 21.1 & 3.9 & $8.8(6.1-12.3)$ \\
\hline$<41$ & Treated & 38.1 & 0 & 0 & 0 & $0(0-1106.6)$ \\
\hline $41-60$ & Treated & 482.2 & 9 & 18.7 & 0.2 & $52.7(24.1-100.1)$ \\
\hline $61-80$ & Treated & 1740.4 & 108 & 62.1 & 2.3 & $46.8(38.4-56.5)$ \\
\hline$>80$ & Treated & 446.5 & 53 & 118.7 & 1.1 & $49.5(37.1-64.7)$ \\
\hline
\end{tabular}

This compared to hospital acquired infections isolated in the background population as comparable data were not available for community acquired infections. 
Table 3 The proportion of pathogens isolated in the 317 cases of bloodstream infection in 277 patients with CLL, 147 events in 126 treatmentnaïve $(\mathrm{TN})$ patients and 170 events in 151 treated patients.

\begin{tabular}{|c|c|c|c|c|c|c|c|}
\hline & $\begin{array}{l}\text { Treatment- } \\
\text { naive }\end{array}$ & Treated & 41-60 (HAI) & 61-80 (HAI) & $81-100$ (HAI) & All age groups (HAI) & $\begin{array}{l}\text { All age groups } \\
\text { (Any bacterimia) }\end{array}$ \\
\hline Candida spp. & 2.1 & 0.6 & 7.5 & 7.9 & 6.6 & 7.3 & 2.4 \\
\hline $\begin{array}{l}\text { Enterobacter } \\
\text { cloacae }\end{array}$ & 0.7 & 1.8 & 3.5 & 3.1 & 2.4 & 3.1 & 2.2 \\
\hline $\begin{array}{l}\text { Enterococcus } \\
\text { faecalis }\end{array}$ & 1.4 & 4.1 & 5.4 & 5.9 & 6.6 & 6 & 5.0 \\
\hline $\begin{array}{l}\text { Enterococcus } \\
\text { faecium }\end{array}$ & 6.8 & 11.2 & 14.3 & 13.5 & 7.6 & 12.1 & 5.2 \\
\hline Escherichia coli & 24.5 & 24.1 & 16.2 & 20 & 25.8 & 19.4 & 28.9 \\
\hline $\begin{array}{l}\text { Klebsiella } \\
\text { oxytoca }\end{array}$ & 2.7 & 1.8 & 2.5 & 2.7 & 2.4 & 2.5 & 2.2 \\
\hline $\begin{array}{l}\text { Klebsiella } \\
\text { pneumoniae }\end{array}$ & 3.4 & 5.3 & 6.4 & 6.2 & 5.4 & 6.1 & 6.9 \\
\hline $\begin{array}{l}\text { Listeria } \\
\text { monocytogenes }\end{array}$ & 2.7 & 2.9 & NA & NA & NA & NA & \\
\hline Other & 26.5 & 27.1 & 23.6 & 21.7 & 19.4 & 22.7 & 25.3 \\
\hline $\begin{array}{l}\text { Pseudomonas } \\
\text { aeruginosa }\end{array}$ & 6.8 & 4.1 & 3.1 & 4.2 & 4.5 & 3.9 & 2.9 \\
\hline $\begin{array}{l}\text { Staphylococcus } \\
\text { aureus }\end{array}$ & 9.5 & 9.4 & 17.5 & 14.8 & 19.3 & 16.9 & 12.9 \\
\hline $\begin{array}{l}\text { Streptococcus } \\
\text { pneumoniae }\end{array}$ & 12.9 & 7.6 & NA & NA & NA & NA & 6.2 \\
\hline
\end{tabular}

This compared to the proportion of hospital acquired infections (HAI) isolated in the background population (ref: https://doi.org/10.1017/ice.2017.1) and the proportion pathogens found in blood cultures in the total population (ref: https://doi.org/10.1016/j.cmi.2014.11.018).

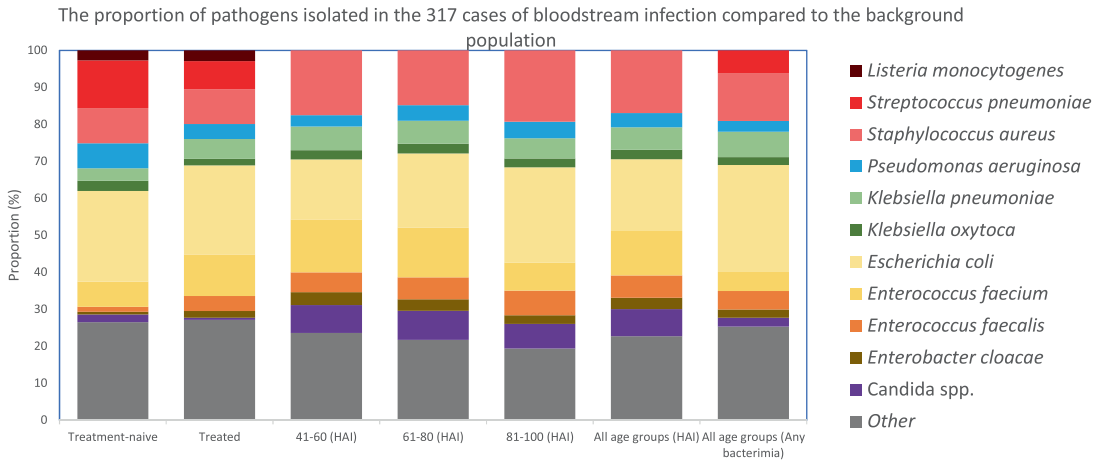

Fig. 3 Proportion of pathogens isolated in the 317 cases of bloodstream infection in 277 patients with CLL, 147 events in 126 treatment-naive patients and 170 events in 151 treated patients. This compared to the proportion of hospital acquired infections (HAI) isolated in the background population (ref: https://doi.org/10.1017/ice. 2017.1) and the proportion pathogens found in blood cultures in the total population (ref: https://doi.org/10.1016/j.cmi.2014.11.018). 